\title{
The Premature Burial of Natural Monopoly: Telecommunications Reform in Australia
}

\author{
John Quiggin
}

\begin{abstract}
A USTRALIA'S telecommunications system has undergone radical reform since 1991. Indeed, along with New Zealand, Chile and Guatemala, Australia is viewed as one of the leaders in telecommunications reform (Spiller \& Cardilli, 1997). The former public monopoly has been corporatised, taking the name Telstra, and partially privatised. Competition has been fostered through the introduction of a private competitor, Optus, in 1991 and the removal of all restrictions on entry in 1997. Owners of infrastructure (in practice, primarily Telstra) have been subject to regulation requiring the provision of network access to competitors on favourable terms.

Although much of the present policy framework was embodicd in the Telecommunications Act 1991, the views of governments and telecommunications regulators have evolved over time. Moreover, there has been a complex interaction between telecommunications-specific policy and the general framework of national competition policy embodied in the Competition Policy Reform Act 1995 and reflected in the regulatory role of the Australian Competition and Consumer Commission (ACCC). Hence, although it is possible to describe current policies reasonably accurately, it is often difficult to distinguish between outcomes that are the result of deliberate design and those that are unintended consequences of interactions between telecommunications policy and general competition policy.

The central distinguishing element of this policy framework has been the belief that, in order to make the Australian telecommunications system fully competitive, competitors should be encouraged to build complete telecommunications networks to compete with that of Telstra. Here, this approach will be referred to as the policy of 'network duplication'.

Reform of the Australian telecommunications system has not produced the benefits forecast by its advocates. In particular, Telstra has retained its market dominance despite the dissipation of billions of dollars in the development of duplicate infrastructure networks. The rise and fall of the Super League football competition and the decision of the ACCC in October 1997 to bankrupt one firm (Aus-
\end{abstract}

John Quiggin is Australian Research Council Senior Research Fellow in Economics at James Cook University. 
tralis) in order to save another (Optus) are illustrations of the failure of telecommunications policy to produce economically rational outcomes.

The main deficiency in Australian telecommunications policy has been the failure to take adequate account of natural monopoly. Alternative institutional structures, designed to exploit economies of scale and scope, could have yielded both a more competitive market structure and lower industry costs.

\section{Natural Monopoly and the Telecommunications Industry}

The concept of natural monopoly is central to an understanding of telecommunications policy. The concept was first given a theoretically satisfactory definition, based on the idea of subadditivity, by Baumol, Panzar and Willig (1982). A cost function is subadditive when any given total output can be produced more cheaply by a single firm than by two or more separate firms. An industry in which the cost function is subadditive may therefore be regarded as a natural monopoly

Unregulated natural monopoly leads to inefficient duplication. Overinvestment on strategically important routes will be matched by underinvestment in areas where one of the firms has an effective monopoly. Eventually, however, one firm will either merge with its competitors or drive them out of business and the industry will become an actual as well as a natural monopoly. This process of strategic duplication and merger is now taking place in the Australian telecommunications industries, although strategies are complicated by the need to take account of the possible reactions of regulators.

Cost subadditivity in telecommunications. In the case of network goods such as telecommunications, a finer disaggregation of the possible sources of subadditivity is required. Consider a telecommunications enterprise offering local telephone services in a number of districts, long-distance telephone services between those districts and other services such as pay-TV and data communications. Several potential sources of cost subadditivity may be distinguished, including potential cost savings from:

(i) serving more customers in any one of the markets mentioned above;

(ii) serving multiple local markets;

(iii) providing local and long-distance services jointly; and

(iv) providing telephone, data and pay-TV services jointly.

Baumol et al. distinguish between economies of scale (cost savings arising from producing larger volumes of a given bundle of goods and services) and economies of scope (cost savings arising from producing more than one good or service in the same enterprise). In their framework, (i) represents economies of scale and (ii)-(iv) are different forms of economies of scope. However, in the analysis of network 
goods the term 'economies of density' is often used to refer to (i), 'economies of scale' to refer to (ii) and 'economies of scope' to refer to (iii) and (iv).

In addition to these sources of cost savings, network economies arise with communications services because the service becomes more valuable to any given consumer as the number of other consumers connected to the service increases. Network economies may be viewed as consumption externalities opposite in nature to congestion externalities. They are associated with natural monopoly, since the monopolist can internalise the externality.

Unfortunately, the empirical evidence on the extent and nature of economies of scale and scope in telecommunications is ambiguous. Shin and Ying (1992) and Spiller and Cardilli (1997) conclude that telecommunications monopolies are 'unnatural', but others, such as Röller (1990) and Gabel and Kennet (1991), reach the opposite conclusion. Application of Stigler's (1958) 'survivor' principle supports the latter view. Stigler argues that, in general, the survival of a monopoly enterprise faced with actual or potential competition is evidence of scale economies. Despite deregulation in many countries with different policy regimes, incumbent firms have remained dominant in most markets and nearly all local telephony markets (Harrison \& Fisse, 1997).

In this article, it will be assumed that economies of scale, that is, economies of type (i), apply to local services of all kinds, but not to long-distance services. No assumption will be made about the presence or absence of economies of types (ii) to (iv). The problem for policy-makers is to design a framework which minimises restrictions on competition while ensuring that economies of scale are captured and that any available economies of scope can be exploited.

Policy response to natural monopoly. Until recently, the most common response to the problem of natural monopoly was public ownership of monopoly enterprises. Since the early 1980s, however, it has increasingly been assumed that market discipline is adequate even in situations of natural monopoly.

A theoretical development supporting this view was the idea of contestable monopoly, developed by Baumol et al. (1982) who stressed the importance of potential entry. Baumol et al. supplemented the standard consideration of barriers to entry by consideration of barriers to exit, that is, of sunk costs. They showed that if there were no barriers to entry or exit, the only sustainable set of prices for a natural monopoly would be the Pareto-optimal set of Ramsey prices."

This theoretical point was taken by many policymakers to be an all-purpose argument for laissez faire. As Baumol and Willig (1986:10) state:

... before anyone can legitimately use the analysis to infer that virtue reigns in some economic sector and that interference is therefore unwarranted,

\footnotetext{
${ }^{1}$ The set of Ramsey prices (or, more precisely, markups over marginal cost) that minimise welfare losses while covering average costs is analogous to the optimal set of commodity taxes required to raise a given revenue. The solution, derived by Ramsey (1927), is to make the tax or markup for each good inversely proportional to the elasticity of demand.
} 
that person must first provide evidence that the arena in question is, in fact, highly contestable.

Unfortunately, this requirement has been ignored by many participants in the Australian policy debate. The term 'contestable' has been used loosely to refer to any market in which restrictions on entry have been relaxed or removed, without any attempt to examine the presence or absence of sunk costs, and hence the likelihood of an outcome free from monopoly pricing problems. The sloppy usage of terms like 'contestability' reflects a more general acceptance, on a basis of faith rather than economic analysis or empirical evidence, of a belief that competition, or merely the threat of competition, will always and everywhere generate socially optimal outcomes.

Sloppy use of contestability theory has been supplemented by wishful thinking about technology, drawing on the claims of writers such as Toffler (1980) of a 'third wave' of post-industrial society in which technology is inherently biased towards small-scale production, and therefore towards competitive outcomes. Oddly enough, the paradigm chosen by Toffler is the microcomputer industry, in which more than 80 per cent of the market is controlled by a single operating system (Microsoft Windows) using central processing unit chips supplied by a single firm (Intel).

Disregarding the inconsistency of claiming that a monopolistic industry will generate a competitive future, advocates of the proposition that technology has rendered the concept of natural monopoly obsolete focus on evidence of convergence between the previously separate computer, television and telecommunications industries. Although most of these industries have historically been either oligopolies or natural monopolies, it is asserted that convergence between them will result in a competitive free-for-all in which regulation will be unnecessary, or perhaps impossible.

Yet there are no grounds for supposing that the concept of natural monopoly will be any less relevant in the future than it has been in the past. Technological change may allow competition in previously monopolistic industries, but it may also generate new sources of natural monopoly.

\section{The Process of Telecommunications Reform}

As in most other OECD countries, Australian telecommunications services were provided, until the 1980 s, by a government-owned monopoly. Significant reforms, directed towards strengthening the government monopoly model, rather than towards market competition, had taken place during the 1970 s. The main reform was the replacement of the former Postmaster-General's Department, under which telecommunications and postal services had been organised on public service lines, by two profit-making statutory corporations, Telecom and Australia Post. These reforms were highly successful in raising productivity and profitability (Industries Assistance Commission, 1989) although critics argued that, even after these gains, the 
enterprises were well below world best practice (Swan, 1990; Bureau of Industry Economics, 1992).

The first move towards free-market reform came with the Davidson Report (Committee of Inquiry into Telecommunications Services in Australia, 1982), which recommended that private networks be permitted to interconnect with the public network and resell excess capacity. Although the Report was initially rejected, its main recommendations were adopted in the statement issued in 1988 by Gareth Evans, then Minister for Communications, which expressed the government's desire for more extensive competition in the telecommunications sector and proposed corporatisation of public telecommunications enterprises. Under the Australian Telecommunications Corporation Act 1989, Telecom was required to follow 'clearly defined commercial principles and objectives'. In 1992, Telecom and OTC were merged to form the Australian and Overseas Telecommunications Corporation, subsequently renamed Telstra, a corporation in which the government initially held all the shares.

A new regulatory framework for the telecommunications market was introduced through the Telecommunications Act 1991. Under this Act, a single competitor for Telstra was admitted to the general telephony market. The successful tenderer was called Optus. As part of the entry conditions, Optus was required to purchase the Aussat satellite system, paying the government more than its market value. The premium was, in effect, a licence fee (Maddock, 1992). Optus was permitted to compete with Telstra in all areas of telephone service. The duopoly regime was intended as an interim measure on the way to more open competition in 1997 (Brown, 1996). The Australian Telecommunications Authority (Austel, now the Australian Communications Authority) was established to regulate prices and conditions of service. Austel was also required to establish the access rules that determined how much long-distance carriers would pay for the access to Telstra's local network that was needed to complete calls.

It gradually became apparent that the government had adopted a policy of network duplication rather than hoping that the mere threat of entry would force Telstra to set prices for access to its network at a level consistent with competitive outcomes. The first clear indication of the government's intentions came with the decision to establish three separate networks for digital mobile telephony. To induce Optus and Vodafone to establish digital networks, the government promised to phase out the existing analog network by 2000 . The irony of promoting competition in one service by prohibiting the provision of another appears to have escaped those responsible for this decision.

The natural conclusion of reforms leading to a competitive telecommunications market would be the withdrawal of government from the telecommunications industry. In 1996, one-third of the public shareholding in Telstra was sold through a public float. Legislation for the complete privatisation of Telstra was introduced in 1998, but was defeated in the Senate. 


\section{The Outcomes of Reform}

Despite radical changes in telecommunications policy, changes in the telecommunications market, particularly for services to residential users, have been modest. Moreover, the limited increase in competition that has occurred has been achieved at the cost of substantial dissipation of resources in strategic investments. Some of the more obviously unsatisfactory outcomes of reform are listed below.

- Telstra has remained officially dominant in all markets except those for mobile and international telephony, and its monopoly of local telephony has remained intact.

- Public control over Telstra's actions has been reduced through corporatisation and partial privatisation (see below).

- Telstra's quality of service has declined (Australian Communications Authority, 1998) even though technological improvements should have led to an increase in reliability.

- Price levels continue to be determined by regulation rather than competition. In most years, Telstra has reduced prices by exactly the amount required to meet the price caps imposed under regulation (Austel, various years; Albon, 1998).

- After racing to construct parallel hybrid-fibre cable networks for pay-TV services, Optus and Telstra halted their rollouts in 1997 leaving two incomplete, but largely overlapping, networks.

- Similar parallel networks for digital mobile telephony have failed to match the coverage of the existing analog mobile phone network.

- The analog mobile phone network is to be compulsorily shut down.

- To provide content for pay-TV networks, duplicate rugby league competitions were operated in 1997, providing entertainment services considerably less valuable than that of a unified competition, but at much greater cost.

- Average prices have fallen, but only at the same rate as before reform took place.

Most of these outcomes are evident to any observer. But since it has often been claimed that competition has resulted in lower prices, it may be worth examining this issue in more detail. The price cap imposed on Telstra for local and long-distance services required a 4.5 per cent annual reduction in real prices, very similar to the rate of reduction achieved over preceding decades (Arena et al., 1992). As Austel (various years) and Spiller and Cardilli (1997) observe, Telstra met the price cap exactly in most years. Albon (1998:323-4) concludes that 'some 
productivity growth appears to have flowed through to excessively higher profits and maintenance of higher costs rather than price reductions'.

Some of the unsatisfactory outcomes of reform, such as the Super League fiasco and the failure of plagued Optus's attempts to enter the market for local telephony, may be put down to bad luck or bad management. But all the policy failures listed result largely from a failure to take account of the importance of natural monopoly in telecommunications networks. Policy-makers who wanted to promote competition accepted that technological developments had rendered the concept of natural monopoly obsolete, and assumed that a competitive market could be legislated into existence.

Moreover, the difficulties involved in managing the industry through regulation rather than government ownership have been underestimated. For example, competition policy is designed to deal with problems of monopoly power in a particular industry. The problems of defining the scope of an industry have been the subject of considerable study. But the study of multimarket interactions, such as those considered by Bulow et al. (1985), is less well developed. The Super League and Australis cases involved multimarket interactions. In the case of Super League, actions intended to enhance monopoly power in telecommunications and pay-TV markets were found to be justified because they increased competition in the rugby league market. In the Australis case, the interests of the shareholders in the Australis payTV venture were sacrificed to promote the (arguably illusory) prospect of competition in local telephone markets. It is impossible to avoid decisions of this kind in dealing with multimarket enterprises having natural monopoly characteristics, but regulators and courts are not well equipped to make such decisions.

\section{Policy Alternatives}

Policy choices in telecommunications, such as the extent to which dominant enterprises should be broken up, often involve trade-offs between competition and the exploitation of economies of scale and scope. In the current debate, competition is assumed to be highly desirable, but the grounds for this assumption are not always clear. Two main arguments may be put forward in favour of competition.

First, under the standard assumptions, competitively determined prices are equal to marginal costs and are therefore consistent with Pareto-optimality, while monopoly prices are set above marginal costs and therefore generate deadweight losses. Where economies of scale and scope are present, this simple analysis does not apply and it is necessary to consider two-part pricing schemes and Ramsey prices (Baumol et al., 1982). In the absence of contestability, reductions in barriers to entry may reduce welfare.

In telecommunications, policies favouring increased competition and lower barriers to entry usually lead to 'rebalancing', that is, a reduction in usage charges and an increase in access charges. Albon $(1988,1991)$ argues that rebalancing, by bringing usage charges closer to marginal costs, will generate substantial welfare gains. However, Quiggin (1997a) observes that access charges are similar in their effects to poll taxes, and generate similar adverse equity effects. The welfare costs 
of tax and welfare measures sufficient to offset these equity effects may exceed the welfare gains from rebalancing.

Second, it is often claimed that competition will yield 'dynamic' improvements in technical efficiency. This claim has little basis in economic theory and little empirical support. Arguments that monopolies are subject to X-inefficiency (Leibenstein, 1966) and rent-seeking (Krueger, 1974) have been supported by little more than anecdotal evidence. This issue is discussed further in Quiggin (1998).

The absence of a clear rationale for competition leads to confusion in policy design, since policies that maximise opportunities for entry will not, in general, be the same as policies that encourage price competition. Policy-makers in Australia appear to have been most concerned about opportunities for entry. The next section of this paper will, therefore, be concerned with ways in which the objective of increasing opportunities for entry could have been achieved at a lower cost in terms of reduced technical efficiency than under the policy of network duplication.

The crucial requirement in achieving technical efficiency is that the gains from natural monopoly should be exploited, rather than dissipated through unnecessary duplication of facilities. I will assume that duplication should be encouraged in the provision of long-distance telephone services and avoided in the physical provision of digital and analog mobile telephone networks, local copper-wire telephone networks and local optical-fibre or hybrid fibre-cable networks for telephony and payTV. This specification of objectives leaves open the boundaries of the natural monopoly sector, but is sufficient to suggest alternatives to the policy of network duplication.

A better duopoly. The effect of network duplication has been to maintain Telstra's monopoly of local telephony, while setting up an effective duopoly in most other segments of the market. I begin by specifying a policy framework that would have yielded greater technical efficiency than, and at least as much competition in all segments of the market as, the policy of network duplication.

The first step, as with the policy of network duplication, would have been the admission of a second long-distance carrier. The second step would have been the replication, for digital mobile telephony and pay-TV, of the common carrier arrangement already in place for analog. That is, a single physical network would be constructed, with both long-distance carriers having access on equal terms. Telstra would be excluded from the provision of pay-TV or other content, and the network would be a common carrier for content providers. Finally, the restrictions on entry by value-added resellers would have been removed immediately, rather than in June 1997. With the removal of the need to provide 'infant industry' protection to Optus in the forlorn hope of building up a full-scale competitor for Telstra, competition from value-added resellers could have been allowed five years earlier.

This framework would have yielded significant efficiency gains by avoiding wasteful duplication in the provision of physical networks, and minimising the dissipation of resources in attempts to secure monopoly control of pay-TV content. It would also have provided more competition than the policy of network duplication. 
Consumers would have had a continuing choice between analog and digital mobile telephone networks, at least until the digital network was clearly superior in coverage and service. By paying for a single connection to the cable network, consumers would have had a wide choice of content providers.

Competition between technologies. Existing policy has focused on promoting competition between enterprises, at the cost of making highly prescriptive decisions about technology, such as the compulsory phaseout of analog mobiles. An alternative would have been to encourage competition between technologies. Analog and digital mobile services are close substitutes and are also a substitute for wires-based local and long-distance services. Competition could have been enhanced, relative to the 'better duopoly' model, by selling the analog network and the right to develop a digital network to separate firms.

Because of the trade-off between competition and economies of scope, it is difficult to say whether the 'competition between technologies' model would have been superior to the 'better duopoly' model. Once again, however, both competition and technical efficiency would be greater than under the policy of network duplication.

A more radical extension of the 'competition between technologies' model would have involved the creation of a new public or private enterprise to provide cable telephone and pay-TV services in competition with Telstra's copper wire network. Such a policy would have involved some difficulties. Telstra would have had an incentive to forestall entry by strategic investment in technologies such as asymmetric digital subscriber lines in areas where cable rollout was likely to take place early. This is the opposite pattern to that required for a cost-minimising solution, which would involve upgrading the existing copper wire network precisely in those places where a cable rollout was uncconomical. However, the waste involved in strategic investments of this kind would be less than that observed under the policy of network duplication.

A breakup of Telstra. A third possibility would be a breakup of Telstra into a set of local monopolies and a long-distance enterprise competing with new entrants, similar to the breakup of the Bell monopoly in the United States in 1976. Within any given market, the effect would be similar to that of the improved duopoly model, except that it would no longer be possible to choose an integrated local and longdistance carrier. Some economies of scope would be sacrificed to achieve more even competition between long-distance carriers.

The idea that natural monopolies should, where possible, be disaggregated into regional components has been popular since the Bell breakup, though the underlying reasoning is not clear. The possibility of 'benchmark competition' has been mentioned but the difficulties in defining comparable benchmarks are formidable (Quiggin, 1997b). The fact that horizontal reintegration (through mergers) of US local telephone services commenced as soon as regulatory barriers to merger were relaxed suggests that breakups involve a loss of economies of scale and scope. 
An assessment. All the options considered above are superior to the policy of network duplication on the criteria of competition and technical efficiency. The policy of network duplication has yielded a modest increase in competition at a high cost in terms of technical inefficiency. Maintenance of the public monopoly would have yielded an outcome superior to that actually achieved. Comparisons among the three are less clear-cut. My tentative judgment is that the improved duopoly model would have yielded significantly increased competition at only a modest cost in terms of technical efficiency and would probably have been the optimal choice.

\section{Corporatisation, Privatisation and Regulation of Telstra}

In all the alternatives considered above, Telstra would remain the dominant supplier of local telephone services, just as it is under the policy of network duplication. Hence, regulation of access prices and final consumer prices would be necessary. The policy issues arising from the need for continued control of the local telephone monopoly are largely independent of the framework adopted for the remainder of the telecommunications system.

The central policy issue is the appropriate organisational form for the local monopoly. For each possible organisational structure, it is necessary to consider an appropriate regulatory framework. In general, control through public ownership is a substitute for regulation, so that the closer the ownership structure is to full privatisation, the more elaborate the system of regulation required to achieve any given divergence from the unregulated monopoly outcome. Thus, the choices of organisational form and of regulatory framework must be made jointly.

The central issue in regulation of monopolies is that of setting maximum prices. For short periods, systems based on a historical starting point, such as CPI mimus $\mathrm{X}$ regulation, may be adequate. However, in the long term, such regulatory systems inevitably reduce to rate-of-return regulation. The result will be a repeated game between the monopoly and the regulator (acting as an agent for consumers), in which both sides face substantial risk. Welfare losses are associated with this risk and with rent-seeking attempts to influence regulatory outcomes.

Much of the risk associated with the regulation game is internalised if the monopoly is publicly owned, since the government acts as the representative of both consumers and taxpayers, the owners of the enterprise. A gain to consumers from low prices is balanced by a corresponding loss to taxpayers.

In considering the desirability or otherwise of privatisation, it is necessary to balance efficiency gains from privatisation against the cost of regulatory risk. The critical question is whether privatisation passes the present value test, that is, whether, with an appropriate choice of discount rate, the present value of future income under public ownership exceeds the price that private buyers are willing to pay.

The issue is complicated by the unresolved debate over the relative capacity of governments and private capital markets to bear the risk associated with systematic fluctuations in aggregate output (Hathaway, 1997; Quiggin, 1997c; Grant \& Quiggin, 1998), and hence whether the discount rate should include a large 'equity premium' 
(Mehra \& Prescott, 1985). However, rate-of-retirn regulation effectively insulates monopolies from systematic risk, so that no risk premium is required. Hence, the appropriate discount rate is the rate of interest on government bonds.

The partial privatisation of Telstra fails the present value test. Following the passage of the Telstra (Dilution of Public Ownership) Act 1996, one-third of the public shareholding in Telstra, consisting of approximately $4.3 \mathrm{~m}$ shares, was sold at an average price of $\$ 3.40$, yielding sale proceeds of $\$ 14$ billion. At a nominal interest rate of 6 per cent, the interest saving from repayment of public debt is $\$ 840 \mathrm{~m}$ a year.

Income forgone through privatisation comprises dividends, retained earnings and imputation credits unclaimed by the government. For 1997-98, the first year after partial privatisation, Telstra's total profits were $\$ 3.0$ billion of which $\$ 1.8$ billion were paid as fully franked dividends and the remaining $\$ 1.2$ billion retained (Telstra, 1998). The value accruing to the private shareholders, and forgone by taxpayers, consisted of $\$ 600 \mathrm{~m}$ in dividends, approximately $\$ 240 \mathrm{~m}$ in franking credits, and $\$ 400 \mathrm{~m}$ in retained earnings, for a total of $\$ 1,240 \mathrm{~m}$. Comparison of this opportunity cost with the interest savings from privatisation shows that there was a net loss to taxpayers of $\$ 400 \mathrm{~m}$. Unless 'Telstra's earnings fail to grow in nominal terms, the loss to the public will rise over time.

The abandonment of proposals for full privatisation raises new difficulties. A partially private, partially public enterprise is an unsatisfactory hybrid. Its managers are subject simultaneously to political accountability, for example through freedom of information legislation, and to the fiduciary obligation to put the interests of shareholders ahead of all other concerns (Quiggin, 1996). Each system of accountability is compromised by the presence of the other. For example, claims of commercial confidentiality have been used to override the principle of freedom of information. The present mixed status of Telstra is unsatisfactory. If full privatisation is not to take place in the near future, full government ownership should be restored.

\section{Unscrambling the Egg}

Given the mistakes that have already been made, where do we go from here? There may still be an opportunity to reorganise the Australian telecommunications industry to take account of the implications of its natural monopoly characteristics. The central element of any such reorganisation would be the restoration of full government ownership of Telstra, which would act as a common carrier system for cable TV and local telephony allowing consumers access to all content providers regardless of the carrier supplying their access to the cable network. This would permit the divestiture of Telstra's interest in the content provider Foxtel. Telstra could also be required to divest its digital mobile telephony business, while being allowed to continue offering analog services beyond 2000 .

The feasibility of such a reorganisation is constrained by existence of contractual guarantees that policy will not be changed. Most notably, although it is generally recognised that the decision to close down the analog mobile network was a 
mistake, the Labor government set this mistake in concrete through its contracts with the digital carriers, Optus and Vodafone.

The difficulty of fixing past mistakes in telecommunications policy is an example of a more general problem. In many cases where the provision of public services is handed over to the private sector, the profitability of the private provider depends primarily on political decisions. Hence, the private provider must demand either a risk premium or a guarantee against future adverse political decisions.

In most cases, politicians eager to secure a politically attractive deal have found it easier to provide the guarantees and leave their successors to deal with the consequences. Binding the hands of future governments in this way is undemocratic and bad policy. If such guarantees are required to attract private providers of services, it is best to keep those services in the public sector.

\section{Concluding Comments}

Australia, like New Zealand and the United Kingdom, has undergone radical microeconomic reform over the past 20 years. Yet there is no clear evidence that this reform has resulted in an increase in the sustainable rate of economic growth. An analysis of Australian telecommunications policy suggests a partial explanation for this unsatisfactory outcome. Much of the potential benefit to be derived from reform of the telecommunications industry has been dissipated in wasteful and technically unnecessary investment in duplicate networks. This is the natural result of policies based on a naive enthusiasm for competition and wishful thinking about the death of natural monopoly.

\section{References}

Albon, R. (1988), 'The Welfare Costs of the Australian Telecommunications Pricing Structure', Economic Record 64(185): 102-12.

(1991), 'Evaluating Telecom's Cross-Subsidies: Political Favours at a Heavy Cost?', Australian Economic Papers 30(56): 10-20.

(1998), 'The Effects of Microeconomic Reform in Telecommunications', pp. 313-30 in Productivity Commission (ed.), Microeconomic Reform and Productivity Growth, Canberra, Ausinfo.

Arena, A., J. Bahtesevanoglou \& S. Branton (1992), The Importance of Telecommunications in Australia's Economic Development and the Likely Effects of Telecommunications Reform, Austel Occasional Paper, Economics 1, AGPS, Canberra.

Austel (various years), Competitive Safeguards and Carrier Performance, AGPS, Canberra (Report to the Minister for Communications).

Australian Communications Authority (1998), Telecommunications Performance Monitoring Bulletin No. 4, Melbourne Central Office.

Baumol, W., J. Panzar \& R. Willig (1982), Contestable Markets and the Theory of Industry Structure, Harcourt Brace Jovanovich, New York.

Baumol, W. \& R. Willig (1986), 'Contestability: Developments Since the Book', Oxford Economic Papers 38(Supplement): 9-36. 
Brown, A. (1996), Reform and Regulation of Australian Telecommunications, School of Economics, Griffith University, Brisbane (Working Paper No. 5).

Bulow, J., J. Gcanakoplos \& P. Klemperer (1985), 'Multimarket Oligopoly: Strategic Substitutes and Complements', Journal of Political Economy 93: 488-511.

Bureau of Industry Economics (1992), International Performance Indicators - Telecommunications, AGPS, Canberra (Research Report 48).

Committee of Inquiry into Telecommunications Services in Australia (1982), Report, AGPS, Canberra (Davidson Report).

Gabel, D. \& D. Kennet (1991), Estimating the Cost Structure of the Local Telephone Network, National Regulatory Research Institute, Ohio State University, Columbus, Ohio.

Grant, S. \& J. Quiggin (1998), 'The Equity Premium Puzzle and the Privatisation Paradox', paper delivered at a Conference on Industry Economics, Australian National University, Canberra (July).

Harrison, K. \& B. Fisse (1997), 'International trends in telecommunications regulation: moving away from the New Zealand model', Gilbert \& Tobin Lawyers, paper commissioned by Optus Communications, http://www.gtlaw.com.au/gt/bin/frameup.cgi/gt/pubs/internationaltrends.html.

Hathaway, N. (1997), 'Privatisation and the Government Cost of Capital', Agenda 4: 155-64.

Industries Assistance Commission (1989), Annual Report 1988-89, AGPS, Canberra.

Krueger, A. (1974), 'The Political Economy of the Rent-Seeking Society', American Economic Review 64: 291-303.

Leibenstein, H. (1966), 'Allocative Efficiency vs X-efficiency', American Economic Review 56: 39245.

Maddock, R. (1992), 'Microeconomic Reform of Telecommunications: The Long Road from Duopoly to Duopoly', pp. 243-59 in P. Forsyth (ed.), Microeconomic Reform in Australia, Allen \& Unwin, Sydney.

Mehra, R. \& E. Prescott (1985), 'The Equity Premium: A Puzzle', Journal of Monetary Economics 15(2): $145-61$.

Quiggin, J. (1996), 'Partial Sale: Worst of All Options', Communications update 119: 4-5.

- (1997a), 'Efficiency versus Social Optimality: The Case of Telecommunications Pricing', Information Economics and Policy 9: 291-308.

- (1997b), 'Why Have the Returns to Microeconomic Reform Been So Disappointing?', paper presented at Conference on Public Sector Efficiency Measurement, Centre for Applied Economic Research, University of New South Wales, Sydney.

- (1997c), 'The Equity Premium and the Government Cost of Capital: A Response to Neville Hathaway', Agenda 4: 475-88.

— (1998), 'Micro Gains from Micro Reform', Economic Analysis \& Policy (forthcoming).

Ramsey, F. (1927), 'A Contribution to the Theory of Taxation', Economic Journa/37(1): 47-61.

Röller, L. (1990), 'Proper Quadratic Cost Functions with an Application to the Bell System', Review of Economics and Statistics 72: 202-10. 


\section{John Quiggin}

Schumpeter, J. (1961), The Theory of Economic Development, Oxford University Press, London.

Shin, R. \& J. Ying (1992), 'Unnatural Monopolies in Local Telephone', Rand Journal of Economics 23(2): 171-83.

Spiller, P. \& C. Cardilli (1997), 'The Frontier of Telecommunications Deregulation: Small Countries Leading the Pack', Journal of Economic Perspectives 11(4): 127-38.

Stigler, G. (1958), 'The Economies of Scale', Journal of Law and Economics 1: 54-71.

Swan, P. (1990), 'Is Wealth Created or Destroyed: A Contracting Cost Evaluation of the Proposed Merger of Telecom and OTC, Australian Graduate School of Management, University of New South Wales, Sydney (working paper).

Telstra (1998), Telstra Annual Results \& Operations Review, 30 June 1998, http://www.investor.telstra.com.au/fin/ann_res.htm.

Toffler, A. (1980), The Third Wave, Collins, London.

I am grateful to two anonymous referees for helpful comments. 